\title{
LEVERAGING ACADEMIC AND VOCATIONAL PERFORMANCE THROUGH SELF-EFFICACY
}

\begin{abstract}
The majority of research examining the impact of self-efficacy on performance across a variety of settings has provided evidence to validate the claim that agency beliefs facilitate human achievement. However, such inquiries have focused within a single domain of functioning. The present study explores the influence of agency beliefs on academic success and the counteraction of the lack of decisiveness in the case of career choice, also known as career indecision. The first part of the paper is conceptual and provides the reader with the theoretical background behind both constructs. The quantitative analysis supported the existence of a bi-directional relationship between the study variables. The last section of the paper is devoted to the qualitative investigation and discussion of the implications prompted by our examination and reveals several noteworthy conclusions: the inability of the participants to extend their agency beliefs from one domain of functioning to another domain without initial guidance and the lack of a clear vision of a future career path stemming from insufficient career counselling.
\end{abstract}

Keywords: self-efficacy, academic performance, vocational pursuits, qualitative analysis, quantitative analysis, career indecision.

\section{INTRODUCTION}

Recent decades mark an era of extensive research into the impact of self-constructs and affective variables on both developing academic buoyancy and displaying favourable vocational behaviours. This tendency within the inquiry seems to be entirely justified nowadays as the volume of young people attempting to effectively juggle the demands of higher education with remaining professionally active is constantly growing. According to Gati et al. (1996), much of the success in both realms of human existence appears to be the result of the favourable combination of a number of developmental tasks. In both domains, however, it is possible to identify cases of exceptionally successful individuals who produce desired outcomes in a somewhat effortless manner, whereas their less fortunate counterparts fail to match the requirements of an endeavour, resulting in withdrawal behaviours rather than effort intensification. Even though the literature on the subject abounds with examples of variables capable of accelerating the likelihood of auspicious conduct, no consensus was reached that would promote one factor as the ultimate performance facilitator. Nevertheless, it appears that the central focus of the inquiry remains on self-efficacy as, to this day, the concept is believed to be one of the major predictors of performance, regardless of a setting

\footnotetext{
${ }^{1}$ Arkadiusz Pietluch, MSc, Institute of English Studies, University of Rzeszow, Al. mjr. W. Kopisto
} 2B, 35-315 Rzeszów; e-mail: arekpie122@gmail.com. ORCID: 0000-0001-8260-9001. 
(Oldham, 2016). In this paper, our attention will be devoted specifically to scrutinising the extent to which well-developed agency beliefs may leverage one's performance in the areas of human functioning specified above as well as the capacity of the notion to remedy the cases of career indecision amongst vocationally active students of English as a foreign language.

\section{THEORETICAL BACKGROUND}

Bearing in mind that self-appraisals regarding one's capacity to succeed ebb and flow throughout time, predicting the likelihood of behaviour execution seems to be a profoundly arduous task. In efforts to account for the way human beings estimate the sufficiency of their skills and knowledge in producing desired attainments, in the late 1960s, Albert Bandura coined the construct of self-efficacy. Although, in its original sense, the concept was designed to better comprehend the nature of human performance within the domain of sport, due to its enormous practical potential, self-efficacy was soon encompassed within the fields such as education, health, and career choice. In the view of Schwarzer and Warner (2013), self-efficacy reflects the positive belief that one can successfully perform novel or challenging tasks conducive to a desired attainment. This, in turn, allows such individuals to execute a certain degree of control over constantly fluctuating circumstances surrounding their existence by means of their own behaviour. Importantly, expectations upon personal efficacy are believed to leverage numerous aspects of one's performance, including decision-making and goal-selecting processes, the volume of effort one is willing to contribute to producing an outcome, and the overall level of resilience a person displays in the vicinity of adversities. The majority of empirical investigations into the subject matter is consistent as to the claim that high value of self-efficacy may be a crucial mediator of behavioural change and, by the same token, accounts for the success of one's undertakings. It is not illogical to assume that those assured of their own ability to meet requirements of a task are more persistent in their pursuits and display more grit once difficulties arise as opposed to their counterparts lacking efficacy who display a tendency to cease their efforts prematurely rather than sustaining their commitment to a cause. Bandura (1991) asserts that people who are confident their abilities would suffice in pursuing a goal approach troublesome endeavours as areas for further development rather than threats to be avoided. In the case of efficacious people, initial challenges are not likely to possess a discouraging impact on a person's readiness to perform as the engagement of such individuals is propelled by a genuine desire to actualise one's potential. Furthermore, demanding pursuits are believed to stimulate one's beliefs of efficacy and therefore individuals with well-instilled personal agency rarely delimit the pool of potential activities by discriminating undertakings which would pose a threat to one's sense of self. Beyond any doubt, such attitude would be desirable in the field of career choice, with several studies confirming the positive correlation between agency beliefs and various indices of career choice behaviour, for instance, variety of perceived options, expressed interests, and vocational preferences (Wheeler, 1983; Lent et al., 1984). On the other end of the spectrum, those lacking assurance regarding their capacity to perform successfully are most typically reluctant towards new activities, let alone endeavours one may perceive as challenging. Following Bandura and Locke (2003), such individuals have lower aspirations in general and tend to lower their goals even further should out-turns be lacking. Instead of explaining initial failures in terms of inadequate effort or yet insufficient skills and knowledge, people 
who are beset by the lack of efficacy attribute unsatisfactory proceedings entirely to factors of external nature and visualise bleak scenarios, leading to the deficiency of motivational impetus and, ultimately, task abandonment. Even though such individuals may, in fact, possess the skillset required to produce a desired outcome in the long run, the lack of foundational persistence in an inept attempt to preserve one's self-image significantly reduces the possibility of delivering favourable performance.

It has become a commonplace to discuss the notion of self-efficacy in terms of three different dimensions, namely magnitude, strength, and generality. The magnitude element refers to the beliefs an individual holds regarding the level of task difficulty within one's perceived reach. Whereas in the case of uncomplicated undertakings people possess similar efficacy levels, more demanding and intricate pursuits may cause for some entities to doubt the likelihood of goal attainment. Turning now to the second factor, Schwarzer and Warner (2013) allege that the dimension of strength pertains to how robust are the self-efficacy beliefs of a person. As previously mentioned, in the face of challenges, ill-efficacious people tend to withdraw from a task rather than intensify their efforts. Additionally, should an individual lack the self-assurance as to one's capacity to succeed, regardless of an endeavour, failure further undermines the belief that the task at hand is indeed achievable. The last realm of self-efficacy that is generality addresses the degree to which self-efficacy expectations are generalised across various life situations (Lunenburg, 2011). Most individuals with well-developed agency beliefs are capable of extending their confidence to other domains of functioning and, similarly, the lack of such certainty would also permeate from one level of existence to another.

Bandura (1997) posits that one's beliefs regarding self-efficacy expectations may stem from four principal sources, including mastery experiences, vicarious learning, verbal persuasion, and emotional cues. Past performance accomplishments, which in the seminal work of Bandura are referred to as enactive mastery experiences, serve as indicators of one's aptitude to succeed and are believed to be crucial components in accruing efficacy information. Basing on experiences accumulated during the lifespan, a person is capable of assessing whether one's skills and knowledge would be sufficient in producing favourable outcomes in the case of perspective endeavours. On logical grounds, acquiring control within a specific domain of existence would embolden a person to unhesitatingly approach further challenges. As postulated by Reddan (2015), success builds a robust belief in one's personal efficacy and failure undermines it, especially if failures occur before a sense of efficacy is firmly established. This is not to say, however, that experiencing setbacks in one's undertakings possesses a solely detrimental impact on the overall quality of performance. To Bandura's mind (1997), some difficulties in human pursuits indicate that success usually requires persistent effort. Overcoming individual limitations through effort intensification rather than attributing the lack of results to external adversities allows a person to gradually develop one's tenacity and diminishes the disheartening impact of challenges one would regularly experience in the case of distal and demanding pursuits. Moving on to the concept of vicarious learning, it is yet another potent source of efficacy beliefs. Building on the principles of behaviour imitation, Bandura (1997) claims that the observation of people attempting to produce outcomes which hold relevance to an individual and corresponding consequences of a perceived behaviour may increase a person's beliefs in their own capability to master similar tasks with comparable effect. Not only does such an observation boost one's agency self-conceptions but also equips an observer with behavioural strategies required to accomplish desired goals or to tackle 
adversities separating an individual from reaching one's full potential (Wise and Trunnell, 2001). At this point, it would also be recommendable to highlight the importance of perceived resemblance between a model and an observer, as the degree of likeness plays a fundamental role in behavioural modelling. The potential of using the vicarious experience as an efficacy-building apparatus relies immensely on the similarity between observed behaviour and desired outcomes a person wishes to produce. Bandura (1997) postulates that the greater the perceived similarity between an individual and a model, the more persuasive his or her successes and failures will be. Turning now to the notion of social persuasion, the assurance regarding one's capabilities may also emanate from the faith other people express in an individual's ability to perform successfully. It may seem therefore that the concept in question is Bandura's attempt to address the volume of influence a person's significant others may exercise over the quality of one's proceedings. Reddan (2015) suggests that verbal reinforcement is effective in enhancing and maintaining a sense of agency if the desired outcome is within realistic boundaries. With this in mind, genuine encouragement, gradually increasing an individual's confidence in the sufficiency of his or her coping abilities, may indeed contribute to developing well-established efficacy beliefs provided such feedback is supplied by people a person considers influential. The last source of agency beliefs, emotional cues, concerns the impact of somatic messages conveyed as the result of physiological and emotional states a person experiences. Damasio et al. (1991) outline that emotional reactions human beings experience, in no small margin, shape the decision-making processes. Much in a similar vein, Bandura (1997) declares that it is not the sheer intensity of experience but rather human interpretation of a state that influences our actions. Whereas positive emotional cues evoked by the possibility to perform an action would encourage persistence and boost one's efficacy beliefs, ruminative thoughts are believed to hamper the likelihood of successful performance. More specifically, self-efficacy may be amplified by reducing the extent to which negative feelings of anxiety or stress impact the performance of a person.

Having completed our discussion upon the concept of self-efficacy, let us now focus on yet another concept which is of tremendous importance for this paper, namely career indecision. The term, in its essence, refers to a broad array of difficulties an individual may experience when making a vital decision regarding his or her career. Chartrand et al. (1994) define career indecision as a developmental problem within the career maturation process that has its origin in the lack of information about one's self. Notably, such issues may arise not only prior to the decision-making processes but also when a person is already pursuing a well-defined, specific career path. Even though, initially, career indecision was viewed as a one-dimensional dichotomy, with people being described as either capable or incapable of making proper career decisions, the notion is now regarded as a multi-faceted phenomenon, with taxonomy including aspects of cognitive, personal, and emotional nature. The lack of decisiveness may stem from various sources, however, it seems logical to assume that people assured of their own capacity to succeed would experience fewer issues embracing a demanding career path. With the scope of our research in mind, in the sections below, our attention will be devoted to scrutinising the extent to which well-developed agency beliefs can counteract the lack of decisiveness amongst vocationally active students of English as a foreign language as well as the impact of self-efficacy on the academic performance of the aforementioned group. 


\section{THEORETICAL FOUNDATIONS AND RESEARCH QUESTIONS}

On the basis of the theoretical discussion, one can observe that there has been some effort to explore the exact nature of correlation between self-efficacy and performance in a variety of settings, including academic performance (Lane and Lane, 2001; Artino, 2012) and vocational contexts (Betz and Voyten, 1997; Creed et al., 2005). The studies in question rendered sufficient evidence to account for the claim that indeed well-established agency beliefs can leverage one's performance even in the case of particularly troublesome undertakings. Bearing in mind that self-efficacy is hardly a one-dimensional concept, one would expect that the notion coined by Bandura may stimulate a person's proceedings in both contexts simultaneously. The review of relevant literature, however, revealed that such multipurpose examinations, combining these two crucial fields of human functioning, are currently scarce. In efforts to partially remedy the aforementioned gap, the present study aims at exploring the shape of self-efficacy beliefs amongst vocationally active students of English as a foreign language and assessing the influence of such beliefs on the results attained by the group. On these grounds, we may move towards the formation of the following three research hypotheses:

1) There exists a direct correlation between a well-developed sense of self-efficacy and academic performance;

2) Individuals with positive self-efficacy beliefs are less likely to experience negative rumination with regards to vocational activities;

3) People are capable of extending agency beliefs stemming from one source to other domains they deem relevant for experiencing the feeling of success.

\subsection{Sampling}

The data collection took place from May to June 2019 and the sample of this study was composed of 72 vocationally active individuals currently employed at one of the major corporate businesses in Rzeszow. In order to ensure that our group was homogenous in its nature, all participants were, at the time of the inquiry, pursuing a Bachelor's degree in English Philology. The subjects were assured that their participation was to be voluntary and that it would not affect their final grade in any way. The sample group consisted of 33 $(45,83 \%)$ male and $39(54,16 \%)$ female subjects, with the age range between 20 to 38 .

\subsection{Instruments}

Participants' sense of self-efficacy was appraised through a standardised version of the General Self-Efficacy Scale (GSES) test derived from Schwarzer and Jerusalem (1995). The instrument consists of 12 forced-answer questions and subjects are requested to record their agreement with each item along a 5-point scale suitable for Likert-Type scale analysis. The tool intends to measure different facets of human agency and is based on positively construed sentences, with the total amount of five possible answers ranging from 'not at all true' to 'exactly true'. On top of measuring the general level of efficacy, the questionnaire scrutinises participant's level of resourcefulness, attitude towards adversities, and effort expenditure tendencies. The test was chosen not only due to its extensive flexibility in measuring different aspects of efficacy beliefs but also due to the availability of large corpus of results, with the mean score oscillating around 0.88 for the individuals aged 20 to 50 . The internal consistency of the instrument in this particular research project was 0.84 .

In order to better comprehend students' perceived difficulties in anticipating their career path, we have decided to adopt the Career Indecision Scale (CIS) initially developed by 
Germejis and De Boeck (2002). The primary version of the tool consists of 17 items, which are further divided into three sections dedicated to exploring various realms of indecisiveness related to career choice, namely information problems, valuation issues, and outcome expectations. The extensive scope of the instrument allows a researcher to approach the problem at hand in a rather holistic manner, however, its most dominant application is to measure the degree of indecision displayed by a subject. In a manner similar to the previous psychometric test, responses are recorded on a 5-point Likert continuum, with grades ranging from 1 (strongly agree) to 5 (strongly disagree). The analysis of the effectiveness of the scale by Germejis (2002) provides a mean Cronbach's alpha between 0.83 and 0.84 . The current sample produced a Cronbach's alpha of 0.892 for the entire scale, whereas the three dimensions of the career indecision identified before that is information problems, valuation issues, and outcome expectancies provided alpha coefficients of 0.792 , 0.767 and 0,801 respectively.

The academic efficiency of participants was assessed during the final practical English exam. During the assessment, four standard criteria were taken into consideration, namely writing ability, the range and accuracy of vocabulary, the correctness of grammar, and the shape of spoken skills. Such an integrated approach allows a researcher to conduct a relatively consistent and objective assessment of language proficiency as opposed to evaluating a single domain of a target language. Bearing in mind the setting of the test, the assessment procedure was loosely based on the Common European Framework of Reference for Languages description of level C1.

\subsection{Data evaluation and results}

To ensure the accuracy of our data, the reliability of the instruments employed for the purpose of this study was measured by determining the scores of Cronbach's alpha coefficients. Following this stage, Spearman's rank correlation coefficient was applied to peruse the nature of the relationship between our variables. The choice of the correlation method was not coincidental; the results of the Shapiro-Wilk normality test unveiled for our data to be far from typical in a normally distributed population. Table 1 below presents the findings of the test in detail.

Table. 1. Shapiro-Wilk normality test

\begin{tabular}{|l|c|c|c|}
\hline \multirow{2}{*}{} & \multicolumn{3}{|c|}{ Shapiro-Wilk } \\
\cline { 2 - 4 } & Statistics & Df & Relevance \\
\hline General Self-Efficacy (1-5) & .924 & 72 & .025 \\
\hline Career indecision (1-5) & .812 & 72 & .000 \\
\hline
\end{tabular}

It should be noted that although a similar scoring procedure was applied in the case of both instruments, for the Career Indecision Scale, the answers were reverse graded. To be more specific, whereas in the case of the GSES a high score is equated with a well-developed sense of self-efficacy, a similar score in the CIS test possesses rather negative connotations and indicates the presence of ruminative thoughts and the lack of decisiveness with regards to the prospective vocational endeavours. Whilst the mean score 
on the GSES was 44.34 and would indicate firmly established agency beliefs, the analysis of the CIS test provided the result of 23,12 which would, under normal circumstances, lead to the conviction that the majority of the participants were not beset by self-doubts in the domain under scrutiny. The outcomes of the two psychometric tests distributed to our subjects were further explored through Spearman's rank correlation coefficient. Table 2 below offers a concise summary of the test results.

Table. 2. Spearman's rank correlation coefficient

\begin{tabular}{|l|l|c|}
\hline \multicolumn{2}{|c|}{} & Career indecision (1-5) \\
\hline \multirow{4}{*}{ level of General Self-Efficacy (1-5) } & Spearman's correlation & .794 \\
\cline { 2 - 3 } & Correlation coefficient & .000 \\
\cline { 2 - 3 } & $\mathrm{N}$ & 72 \\
\hline
\end{tabular}

The data gathered in the table above seem to support the existence of a strong correlation $(0,794)$ between a high sense of personal agency and the lack of ruminative thoughts yielded by the necessity to define one's future career path. On an additional note, the results stemming from our examination were found to be statistically relevant, indicating that a boost to one's self-efficacy beliefs would be simultaneously followed by a decrease in the likelihood of negative career-related rumination.

Moving on to the last quantitative component of our inquiry that is the correlation between agency beliefs and the success of academic pursuits, the results were, once again, in accord to the study's hypotheses and it was of no surprise that the average result of the academic test was $84.5 / 100$. Specifically, it appears that a high score was more typical for those individuals who reported possessing well-developed agency beliefs, with the Spearman coefficient of 0.847 . Similarly to the former item, the results were found to be relevant from the statistical standpoint. The findings are summarised in Table 3 below.

Table. 3. Spearman's rank correlation coefficient

\begin{tabular}{|c|l|c|}
\hline \multicolumn{2}{|c|}{} & $\begin{array}{c}\text { Academic performance } \\
(0-100)\end{array}$ \\
\hline \multirow{4}{*}{ level of General Self-Efficacy (1-5) } & Spearman's correlation & .847 \\
\cline { 2 - 3 } & Correlation coefficient & .000 \\
\cline { 2 - 3 } & $\mathrm{N}$ & 72 \\
\hline
\end{tabular}


The primary intent of the present study was to expand on a possible correlation between the state of efficacy beliefs, academic results, and the lack of decisiveness in the context of occupational pursuits. The quantitative part of the investigation provided sufficient evidence to account for the validity of the claim that such a correlation indeed exists. On these grounds, it is possible to draw an unyielding conclusion that, in the population under scrutiny, the value of self-efficacy aids individuals in developing coping strategies adequate in counteracting numerous adversities emerging from the pursuits of both academic and vocational nature. In the following section, we shall turn to presenting and discussing the implications of the results.

\section{DISCUSSION AND CONCLUSIONS}

The rationale behind this investigation was to scrutinise the extent to which positive self-efficacy beliefs contribute to developing coping efficiency in two significant realms of human existence, namely academic and occupational setting. The quantitative part of the project seems to render this hypothesis accurate as self-efficacy was found to facilitate a person's performance in both domains. One may assume that, regardless of the source of origin, high personal agency beliefs permeate all aspects of human existence and, consequently, the capacity to overcome adversities developed in one domain overlaps on an individual's ability to succeed in other fields crucial for a person. Surprisingly though, the closer analysis of the results stemming from our questionnaires proves otherwise; although the majority of participants reported well-anchored beliefs as to their capacity to manage the vocational demands, some respondents lacked certainty whether this would indeed contribute to achieving academic success. This, in turn, indicates that in terms of agency building, the population under analysis is generally more inclined to seek mastery in their occupational pursuits rather than academic education. A tentative suggestion here might be that as our research group was predominantly composed of young adults, our subjects are more favourably disposed towards extrinsic reinforcements provided by the successful performance at work and have a lesser need to display efficiency in the academic setting. Having in mind the time limitations of our project, there is most definitely a need for larger-scale studies allowing a researcher to investigate this feeling of inadequacy indepth and determine whether this lack of the capacity to adjust one's efforts in the vicinity of taxing circumstances is a result of the concept of self-efficacy being domain-specific or, for example, the lack of guidance as to how to properly employ coping strategies from one field to the other.

The analysis of the CIS test brings forth another noteworthy observation in terms of the source from which career indecision stems. Some respondents included in the study admitted that they do not possess a clear-cut vision of their desired future vocational activity. Although the group was relatively young and somewhat satisfied with their present working experience, the issue at hand does not only pose an intriguing dilemma for further research work but, more importantly, pinpoints the significant need of the group for career counselling. Additionally, developing agency through experiencing mastery is the most potent source of efficacy beliefs, however, it is also far from being straightforward. Even though some human beings may be fully capable of achieving success in a specific domain, people frequently require initial guidance before self-propelling properties of self-efficacy are activated. Thus, on top of incorporating self-efficacy building techniques to an academic curriculum, it would be recommendable to include elements of career counselling, allowing 
students to explore the available work opportunities in which they can exercise mastery and utilise their potential to the fullest extent possible.

The present study was initiated in an endeavour to examine the extent to which a welldeveloped sense of efficacy facilitates one's performance in the academic setting and reduces the lack of certainty when undertaking decisions crucial for the vocational pursuits. The results yielded by our investigation appear to prove the presence of the presumed correlation, as the mean score of the group was well within the boundaries of the mass corpus data. One of the most interesting findings is that, in the population under scrutiny, a high sense of efficacy in one domain does not seem to pervade other realms crucial for a person but rather our subjects develop their beliefs individually in each aspect of functioning. This outcome, however, may be partially caused by the composition of the sample. Overall, the most important conclusion to be drawn here is that larger-scale longitudinal examinations are still required to investigate the exact impact of efficacy beliefs on various domains of human existence, so that the notion may be better employed as a performance facilitator.

\section{REFERENCES}

Artino, A. (2012). Academic self-efficacy: from educational theory to instructional practice. "Perspectives on Medical Education" 2.

Bandura, A. (1991). Self-regulation of motivation through anticipatory and self-regulatory mechanisms: Perspectives on motivation. "Nebraska symposium on motivation" 38.

Bandura, A. (1997). Self-efficacy: The exercise of control. New York: Freeman.

Bandura, A., Locke, E. (2003). Negative Self-Efficacy and Goal effects Revisited. "Journal of Applied Psychology" 88.

Betz, N., Voyten, K. (1997). Efficacy and outcome expectations influence career exploration and decidedness. "The Career Development Quarterly" 46.

Chartrand, J., Martin, W., Robbins, S., McAuliffe, G., Pickering, J., Calliotte, J. (1994). Testing a level versus interactional view of career indecision. "Journal of Career Assessment" 2.

Creed, P., Prideaux, L., Patton, W. (2005). Antecedents and consequences of career decisional states in adolescence. "Journal of Vocational Behaviour" 67.

Damasio, A., Tranel, D., Damasio, H. (1991). Somatic markers and the guidance of behaviour: Theory and preliminary testing [In:] Levin, H., Eisenberg, M., Benton, A., eds., Frontal lobe function and dysfunction. New York: Oxford University Press.

Gati, I., Krauz, M., Ospiow, S. (1996). A taxonomy of difficulties in career decision-making. "Journal of Counselling Psychology" 76.

Germeijs, V., De Boeck, P. (2002). A measurement scale for indecisiveness and its relationship to career indecision and other types of indecision. "European Journal of Psychological Assessment" 18.

Lane, J., Lane, A. (2001). Self-Efficacy and Academic Performance. "Social Behaviour and Personality: an International Journal" 29.

Lent, R., Brown, S., Larkin, K. (1984). Relation of self-efficacy expectations to academic achievement and persistence. "Journal of Counselling Psychology" 31.

Lunenburg, F. (2011). Self-efficacy in the Workplace: Implications for Motivation and Performance. "International Journal of Management, Business, and Administration" 14. 
Oldham, A. (2016). Predictive Abilities of Past Performance Versus Self-efficacy, Across Contexts and Goal Types. "Honours College Capstone Experience". Owensboro: Western Kentucky University.

Reddan, G. (2015). Enhancing student's self-efficacy in making positive career decisions. "Asia-Pacific Journal of Cooperative Education" 16.

Schwarzer, R., Jerusalem, M. (1995). Generalised Self-Efficacy Scale [In:] Weinman, J., Wright, S., Johnston, M., eds., Measures in health psychology: A user's portfolio. Causal and control beliefs. Windsor: NFER-NELSON.

Schwarzer, R., Warner, L. (2013). Perceived self-efficacy and its relationship to resilience [In:] Prince-Embury, D., Saklosfske, D., eds., Resilience in Children, Adolescents, and Adults. Translating Research into Practice. New York: The Springer Series on Human Exceptionality. Wheeler, K. (1983). Comparisons of self-efficacy and expectancy models of occupational preferences for college males and females. "Journal of Occupational Psychology" 56.

Wise, J., Trunnell, E. (2001). The Influence of Sources of Self-Efficacy Upon Efficacy Strength. "Journal of Sport and Exercise Psychology" 23.

DOI: $10.7862 /$ rz.2020.hss.23

The text was submitted to the editorial office: November 2019.

The text was accepted for publication: June 2020. 